\title{
A União dos Homens de Cor: aspectos do movimento negro dos anos 40 e 50
}

Joselina da Silva

\section{Resumo}

O objetivo deste texto é discutir a respeito de algumas estratégias organizativas empregadas pela União dos Homens de Cor (UHC) - grupo fundado em Porto Alegre em 1943 e que cinco anos mais tarde se ramificava por mais dez estados da Federação -, em diferentes partes do território nacional através dos periódicos da imprensa negra. Este é um exercício teórico na direção de uma análise sobre a construção e de uma identidade racial negra no Brasil, entre os anos 40 e 50, tendo como estudo de caso a UHC. Em primeiro lugar, é delineada a organização dos negros nos anos 40 e 50, numa perspectiva etnográfica e daí são apresentadas algumas reflexôes sobre a UHC. Neste sentido este texto pretende contribuir para com o debate que situa as organizaçóes do Movimento Social dos Negros no tempo sócio-histórico em que estejam localizadas.

Palavras-chave: União dos Homens de Cor, movimento negro, movimento social, negros, anti-racismo, identidade racial, Teatro Experimental do Negro. 


\begin{abstract}
The União dos Homens de Cor: aspects of the black movement in the 40's and 50's
\end{abstract}

The objective of this article is to discuss some organizational strategies implemented by the União dos Homens de Cor (Colored Men's Union) - UHC, which is a group founded in Porto Alegre in 1943 and five years later has been spread to more than ten states, in different places of Brazil through newspapers organized by a Negro press. This is a theoretical exercise towards the analysis of the construction of a black-race identity in Brazil during the 40's and 50's, having the UHC as a case study. In first place, it presents the black organization during this period from an ethnographic perspective and then indicates some reflections on the UHC presented. However, this text intends to contribute to the discussion about the Black Social Movement organizations in the social-historical time they are inserted.

Keywords: Colored Men's Union, black movement, social movements, black people, anti-racism, racial identity, Negro's Experimental Theatre.

\title{
Résumé
}

\section{L'Union des Hommes de Couleur : aspects du mouvement noir des années 40 et 50}

Le but de cet article est débattre quelques stratégies organisationelles utilisées par l'Union des Hommes de Couleur - UHC, un groupe fondé à Porto Alegre, en 1943, qui s'est étendu dans dix autres états de la fédération, cinq ans plus tard, à travers les journaux de la presse noire. Il s'agit d'un exercice théorique pour analyser la construction d'une identité raciale noire au Brésil, dans les années 40-50, en se fondant sur le cas de l'UHC. D'abord, on a esquissé une analyse de l'organisation des Noirs pendant ces années-là, dans une perspective ethnographique ; c'est à partir de cela que nous ferons quelques réflexions sur l'UHC. Dans ce sens, cet article apporte une contribution au débat qui situe les organisations du Mouvement Social des Noirs dans le temps socio-historique où elles se sont produites.

Mots-clés: Union des Hommes de Couleur, mouvement noir, mouvement social, Noirs, anti-racisme, identité éthnique, Théâtre Expérimental du Noir. 
$\mathrm{A}_{\text {Negro Revoltado (Nascimento, 1968), num olhar crítico em }}^{\text {bdias Nascimento, no prefácio à segunda edica do livro } O}$ direção ao passado, classifica, trinta anos depois, de "comportamento demasiadamente conciliador para com a posição dos brancos liberais", o que teria norteado várias atitudes, declaraçôes e conclusões finais do I Congresso do Negro Brasileiro organizado pelo Teatro Experimental do Negro (TEN), em 1950. Alguns autores fazem coro com Abdias quando estudam aquele período. Dentre estes poderíamos destacar Andrews (1991) e Hanchard (1998).

Andrews refere-se a um grande número de jornais que ressurgem na capital paulista, no período pós-Estado Novo. No entanto, de acordo com o autor, esses grupos seriam sensíveis às críticas dos brancos na sociedade paulista e, por conseguinte, preocupavam-se, através de sua imprensa, em deixar clara a sua intenção não conflitada de organizar-se racialmente. Conseqüentemente, optaram por atuar na área da educação, da ajuda mútua e de projetos de solidariedade. Desta forma, o autor aborda a ocorrência de um certo medo de um possível confronto, por parte daquelas lideranças. Para Andrews, nenhum deles teria apresentado um programa ou mesmo organizado alguma ação de cunho político, como forma de reivindicação de direitos individuais ou coletivos.

Outro autor cujo trabalho também se detém a estudar as organizações negras no período pós-Estado Novo é Hanchard (1998). Numa proposta de estudar o Movimento Negro Brasileiro entre 1945 e 1988, o autor acredita que o perfil do movimento negro de congregar diversos grupos e cada qual com prioridades e estratégias diversas, impediram que uma força central fosse carreada no sentido de propiciar uma definição mais clara de objetivos e estratégias, de forma a construir uma coalizão. Como conseqüência, esta desarticulação teria provocado o distanciamento do Movimento Negro de uma tática que se empenhasse nas lutas contemporâneas adotadas por outros movimentos sociais. Por conseguinte, o movimento passa a recorrer a protestos de natureza apenas 
simbólica, em que a cultura afro-brasileira passou a ter papel preponderante.

Reconhecemos a importância, para a organização político-social dos negros brasileiros, das realizações de diversos grupos, no período do pós-guerra, dentre os quais o TEN (criado pelo próprio Abdias) se destacou e foi protagonista em atividades que revitalizaram o espírito coletivo dos negros imbuídos do desejo de mudança. Ao mesmo tempo, o escopo deste texto não comportaria maiores considerações a respeito das análises daqueles autores, cujos trabalhos representam grandes contribuições aos estudos sobre os movimentos sociais dos negros, ainda tão pouco privilegiados pela academia brasileira.

Faz-se necessário, no entanto, situar que aqueles eram anos de conflitos raciais no EUA, os países africanos davam os primeiros passos rumo à independência e o fantasma do racismo e da discriminação racial rondava o mundo do pós-guerra. O Brasil do nacionalismo e da escalada crescente para a modernidade se sobressaía como o lugar da paz racial possível. Exemplo disto é a realização, aqui, dos estudos da Unesco nos anos 50. A partir do final da década de 1940 o cenário nacional é marcado por uma urbanização e uma industrialização crescentes. ${ }^{1}$ As reações imediatas da sociedade conservadora, com suas freqüentes demonstrações de racismo, agilizaram o discurso e a atuação das organizações negras. Paralelamente a isso, o término da ditadura varguista deu lugar às diversas manifestações de democracia, permitindo que algumas das organizações negras, que se mantiveram ativas durante o Estado Novo, se reorganizassem e várias outras fossem criadas, como veremos no tópico seguinte.

\section{O renascimento das organizações negras após o Estado Novo}

O ano de 1945 foi muito fértil na realização de congressos e convenções de partidos políticos. Mas, também, houve reuniōes, congressos e convenções da raça negra. Bem ou mal intencionados, os líderes negros de São Paulo movimentaram-se, fazendo reviver a luta que os nossos antepassados iniciaram com a campanha da Abolição. (Luiz Lobato, Senzala - Revista mensal para o negro, 1946, p. 14)

Reações como estas eram comuns na imprensa da época aquela feita pelos negros - dando conta não apenas da grande mobilização das organizações negras, como também da entrada de um número expressivo de negros nas universidades. 
Convém destacar-se - e isso faço com satisfação - que o negro de Pôrto Alegre está sendo atacado de uma sêde de elevação cultural que muito nos anima. Não é muito raro encontrar-se jovens pretos cursando as escolas superiores. E isso é indício muito significativo, uma recomendação para os negros da cidade. (Heitor Nunes Fraga, Quilombo, jan./jul., 1949:4)

Moura aponta que a partir de 1945 ocorre um Renascimento Negro (Moura, 1989) com o surgimento de grupos de discussão e ação contra a discriminação racial e o racismo. Lutavam também pelo "alevantamento moral da gente negra" que pode ser traduzido como medidas que objetivavam à ascensão social e à destruição do mito de inferioridade racial (fruto das teorias racistas do século anterior e que continuavam a permear o imaginário nacional). Para Andrews no entanto, o que houve foi uma renovação do movimento, já que apesar do banimento da Frente Negra (nos anos 30), os clubes sociais e associações cívicas continuaram a se organizar.

A Associação José do Patrocínio (São Paulo), por exemplo, teria apresentado, em 1941, ao presidente Getulio Vargas, uma documentação solicitando a proibição dos anúncios discriminatórios contra os trabalhadores negros. Seu pedido foi atendido quatorze meses mais tarde (Andrews, 1991). Desta forma, ancoradas na esteira da democratização por que passava o país, aquelas novas organizações negras tinham como objetivo principal cuidar da "redefinição e implantação definitiva das reivindicaçôes da comunidade negra" (Gonzales, 1982:24). Havia um sentimento de euforia e realização coletiva expandido pelo território nacional.

É cedo, muito cedo mesmo para se tentar uma apreciação sociológica ou histórica do importante acontecimento que assinala o surto, ou melhor, o ressurgimento de livre associação do negro brasileiro, sufocado durante vários anos pela orientação política que jugulava a opinião pública do país. [...] Em São Paulo, como no resto do Brasil, o negro se movimentou com o objetivo de retornar ao trabalho pela conquista definitiva daquelas fundamentais, de cidadãos, através de verdadeiros planos de atividades que permitam a realização dos velhos anseios acalentados pela grande família. Está-se portanto no início de uma campanha formidável à qual se deve dar o caráter de uma revolução construtiva, no sentido social e político. (Alvorada, janeiro de 1946, p. 1, São Paulo)

Esta longa citação nos auxilia a entender que o ambiente cultural propiciado pela nova democracia, aliado à insatisfação diante das barreiras raciais impostas aos negros, principalmente no mercado de trabalho (Huntley e Guimarães, 2000), deram oportunidade à realização de eventos que davam visibilidade a uma luta ges- 
tada desde séculos anteriores. Assim, no ano de 1945 (10 a 12 de novembro) marcaram a realização da Convenção Nacional do Negro, em São Paulo (Andrews, 1971), que tinha por objetivo preparar uma plataforma de ação para a constituinte que se avizinhava, lançando um manifesto à nação.

A esse respeito, noticiava a revista Senzala que teriam estado presentes participantes oriundos do Rio de Janeiro, Espírito Santo, Minas Gerais, São Paulo e Rio Grande do Sul, Arnaldo de Oliveira Camargo, um dos palestrantes daquela convenção, escreveu dois meses depois uma coluna que pretendia ser uma síntese dos debates ocorridos naquele encontro. $\mathrm{O}$ autor aludia à formação mestiça do povo brasileiro mencionando as três raças formadoras. Prossegue com a reiteração de que tal formação, aliada à democracia que norteava o país, seriam incompatíveis com as "restriçóes que elementos reacionários e com mentalidade nazi-fascista querem impingir ao nosso povo". Camargo - igualmente a muitos articulistas negros da época - atribuiria à educação e ao aspecto econômico "o problema do negro brasileiro", causados pela escravidão e pela ausência de solidariedade daqueles que alçaram galgar maior ascensão social para com os que não o conseguiram. A partir daí o autor propugna por uma maior união entre os afro-brasileiros e prossegue:

Os negros precisam se unir para reivindicar de fato os direitos que desde há muito já nos são outorgados por lei. Pois é sabido que até hoje os negos são barrados na Escola Militar, na Escola Naval, na Aeronáutica [...]. E o problema não é só de ordem cultural e econômica. É também de caráter social, pois se é vedado na sociedade o acesso de grande parte do elemento negro, nós temos que enfrentar essa sociedade reacionária e anti-cristã, apresentando-lhe a lamentável falha democrática. (Agnaldo de Oliveira Camargo, Senzala, Ano I, no 1, p. 11, janeiro de 1946, São Paulo)

Igualmente, naquele momento de abertura política, a cidade de São Paulo via ser criada a Cruzada Social e Cultural do Preto Brasileiro, o Centro de Cultura Luiz Gama e a Frente Negra Trabalhista. Outra organização fundada naquele período foi a Associação do Negro Brasileiro (ANB), uma das estudadas por Fernandes (1971) no projeto Unesco e por Andrews (1991). Também em São Paulo foram criados vários jornais, dentre eles, o Alvorada, o Niger, o Novo Horizonte, o Mundo Novo, A Tribuna Negra, além da revista Senzala (Bastide, 1971; Andrews, 1991; Hanchard, 1988). Muitos clubes sociais que se espalhavam pelo interior do estado se fortaleceram a partir daí. Outra iniciativa foi a fundação do Teatro 
Experimental do Negro (TEN) de São Paulo, por Geraldo Campos, que após conhecer Abdias Nascimento no Rio, levou-o para a capital paulista. ${ }^{2}$

Dos muitos eventos ocorridos em São Paulo, poderíamos destacar aquele que a cidade de Campinas sediou, em dezembro de 1945: o Congresso Cultural e Artístico dos Negros Campineiros, promovido por dois grupos, os Ferroviários e a União Cultural Artística e Social do Negro. Sob a coordenação de Constâncio Vitorino Filho, tinha como objetivo "debater os problemas ligados à situação do negro e traçar normas de ação em prol da elevação cultural econômica, social e política do elemento afro-brasileiro" (Senzala:30). A independência em relação aos partidos políticos; a unificação das organizações dos negros, visando o desaparecimento de todos os preconceitos contra a comunidade negra e a ascensão cultural e econômica dos negros foram algumas das conclusões às quais chegaram os participantes daquele conclave.

A realização de eventos com ênfase no debate e na formação de uma identidade político-racial se dava com freqüência, inclusive contando com a presença de personalidades da sociedade da época.

Muitas associações tem sido fundadas por todo o país, com o objetivo de elevar o negro culturalmente [...]. O Sr. José da Silva Oliveira fundador da Cruzada Social e Cultural do Preto Brasileiro vem promovendo na capital bandeirante, uma série de conferências com o fito de interessar a sociedade e o próprio negro na causa da sua valorização. Ainda a 14 de julho houve a quanta conferência [...] com a presença de pessoas de relevo na sociedade entre as quais destacava-se o Sr. Cecil P. Cross, cônsul geral dos Estados Unidos.

O Rio de Janeiro, por sua face cosmopolita em virtude de ser Capital Federal, transformava-se em berço de importantes organizações, entre as quais podemos citar o Grupo de Afoxé Associação Recreativa Filhos de Gandhi, o Teatro Experimental do Negro ${ }^{4}$ $(\mathrm{TEN})^{5}$, a União dos Homens de Cor (UHC), a União Cultural do Homens de Cor, o Teatro Popular Brasileiro (TPB), o Renascença Clube e a Orquestra Afro-Brasileira, composta por dezoito músicos. Alguns advogados, médicos e artistas fundaram, em 1959, a União Cultural Brasileira dos Homens de Cor (UCBHC) na Cidade de Duque de Caxias, Baixada Fluminense.

Solidificava-se naquele momento uma imprensa negra na cidade, onde os jornais Quilombo, Redenção e Voz da Negritude eram os principais representantes. Quilombo, com seu subtítulo "Vida, 
problemas e aspirações do negro", dirigido por Abdias Nascimento era o combativo órgão da imprensa preocupado em analisar as conseqüências do racismo sobre a população negra. O espírito organizativo em função da arte e da conscientização racial, mais que a mera inserção na sociedade, era constante no periódico. "Trabalharemos Unidos para um Brasil melhor”, este é o subtítulo do jornal Redenção, dirigido por João da Conceição, que apresentava como princípio a formação educacional do negro a fim de prepará-lo para alçar uma posição superior na hierarquia social.

O terceiro periódico, $A$ Voz da Negritude, era o jornal da UHC de Niterói. A UHC que no Rio de Janeiro tinha a liderança de José Pompílio da Hora, estava presente em pelo menos onze estados do país. Uma outra forma de organização constituída a partir do direito ao lazer e ao espaço associativo tornou possível a criação de clubes sociais negros em diversos pontos do território nacional. No Rio de Janeiro, o pioneiro foi o Renascença Clube, fundado em fevereiro de 1951 (Silva, 2000).

Continuando nesta efervescência, na década seguinte foram realizadas, sob os auspícios do TEN, duas Convençōes Nacionais do Negro. Ambas encaminharam à constituinte, através do então senador Hamilton Nogueira, uma "proposta de inserir a discriminação racial como crime de lesa-pátria” (Huntley e Guimarães, $2000,97)$. Prosseguindo na sua intensa lide organizativa, com eventos marcantes para a atividade política e cultural do negro brasileiro, também sob a batuta do TEN estavam a Conferência Nacional do Negro Brasileiro, o Primeiro Congresso do Negro Brasileiro e foi constituído o Conselho Nacional de Mulheres Negras.

Mais ao Sul, em Santa Catarina, ensaiou -se a criação de uma sucursal do TEN. Lá foi estabelecida e se solidificou a UHC, a respeito da qual falaremos no último capítulo. Porto Alegre registrava, nesse mesmo período, o Centro Literário de Estudos Afro-Brasileiros e os clubes Satélite Prontidão e - desde o século anterior - o Clube Floresta Aurora. Salvador viu nascer, em 1946, a Campanha Pi Racial, cujo objetivo era:

[...] extinguir, anular, abolir o complexo de inferioridade (dos mais escuros); desmoralizar, esclarecer e purificar um falso complexo de superioridade (dos mais claros) para que, por processo educacional justo e perfeito, não haja mais no Brasil, um negro ou branco, mas simplesmente, brasileiro. (Azevedo, 1952:159)

Também lá, havia a UHC estabelecida com diretoria composta por dez membros. 
Em Belo Horizonte atuavam, entre outros, a Turma Auri-Verde e o Grêmio Literário Cruz e Souza (Nascimento, 1999) e a Associação José do Patrocínio. Esta última fundada pelo tenente coronel da Polícia Militar, Antonio Carlos, que realizava, além de atividades recreativas, aulas de artesanato, palestras e aulas turísticas em viagens às cidades cuja história estivesse associada ao negro no Estado de Minas Gerais.

Não é nosso objetivo esgotar aqui a citação de todos as organizações negras daquele período, até porque pesquisas mais ampliadas para este fim estão por ser feitas. Nosso intento é apenas dar uma idéia da grande movimentação no Brasil em torno da denúncia e desmantelamento do racismo e da discriminação racial, ao lado da amplitude - em termos geográficos - das iniciativas coletivas, organizadas pelos negros. Neste sentido, o documento final do I Congresso do Negro Brasileiro (São Paulo) em 1950 apontava para criação de uma Confederação Nacional de Entidades Negras (Costa Pinto, 1952). Independente do fato de haver ou não sido criada aquela confederação, sua mera citação já dá mostras da existência de uma teia de grupos, por todo o território brasileiro, que pudesse vir a sustentá-la.

Todo este cenário de redes, articulações e discussões em torno das relaçôes entre negros e brancos no país, pulsantes a partir dos anos 40 , pode ser percebido através dos periódicos negros. Havia, entretanto, uma constante tensão entre a denúncia do racismo, a discriminação racial, a exclusão em que eram colocados os negros e a reiterada afirmação da especificidade racial do Brasil, no que tangia à miscibilidade cultural e racial garantidoras de paz entre negros e brancos. As declarações de diversos líderes negros eram entrecortadas por linhas que procuravam deixar claro a ausência de práticas racistas, por parte delas:

A União é apolítica, aceitando em seu seio homens de todos os credos políticos e religiosos. E também os homens de todas as cores, inclusive brancos que estejam ligados aos morenos pelo sangue e que tenham sincera simpatia pela causa. (João C. Alves, Quilombo, Ano I, no 1, p. 3, dezembro de 1948)

A razão deste cuidado poderia ser justificada, já que, à primeira vista, seriam estes líderes os inauguradores de uma reflexão e uma práxis desnecessárias e perigosas para os destinos da nação. Referimo-nos ao fato de que o Brasil tradicionalmente construiu uma retórica de não discriminação e de ausência de racismo. Os diversos documentos e estatutos diziam estar abertos a "negros, bran- 
cos epardos", ressaltando o espírito "bumano, democrático e universalista" das organizações negras que procuravam evitar represálias diante de suas demandas reivindicativas em favor dos negros nacionais.

A UHC, por seu turno, não fazia exceção a esta regra, quando afirmava em seu estatuto: "É contra essa injustiça social que o sonho dos negros, pardos e brancos da 'União dos Homens de Côr' está colocado. Não é um sonho separatista - é unitarista, solidarista, cristão social" (José Bernardo da Silva, UHC do Distrito Federal, outubro de 1953). Observemos, então, que não apenas nos documentos finais do I Congresso do Negro Brasileiro (1950) este "espirito conciliador", de que fala Abdias (ao qual nos referimos no primeiro parágrafo deste artigo), podia ser encontrado. Ele estava presente na gênese mesma dos diversos grupos, uma vez que constava do seu estatuto. Nossa hipótese é de que talvez esta fosse uma das estratégias possíveis, encontradas por aquelas lideranças negras, diante do arraigado discurso oficial brasileiro de igualdade entre as raças e a existência de uma democracia racial.

Dizíamos na introdução deste trabalho que nosso objetivo é estudar a UHC, contextualizando-a no "Renascimento Negro" dos anos 40 e 50. Assim sendo, procuramos apresentar uma breve etnografia a respeito de alguns grupos e jornais negros brasileiros nas décadas de 40 e 50, de forma a demonstrar que a criação da UHC incluía-se numa atmosfera de insurgência, reação e discussão por parte das lideranças negras, em diferentes pontos do território nacional. Passaremos agora a abordar a organização a partir da qual surge esta pesquisa e cuja trajetória pretende ser melhor analisada neste trabalho, intitulada a UHC.

\section{União dos Homens de Cor - UHC}

Uma organização destinada à ação contra o preconceito de cor e pelo alevantamento moral e cultural do negro, por via, principalmente, da assistência social. (Pinto, 1952: 302)

Esta rede foi fundada em Porto Alegre, em janeiro de 1943, por João Cabral Alves, que segundo seu estatuto era farmacêutico e articulista. Além dele, assinavam o documento de inauguração mais seis pessoas, sendo cinco homens e uma mulher, com profissões que variavam entre médico, advogados, funcionários públicos e uma doméstica. A UHC contava, cinco anos após sua fundação, com representação em pelo menos onze estados do país: Minas Ge- 
rais, Santa Catarina, Bahia, Maranhão, Ceará, Rio Grande do Sul, São Paulo, Espírito Santo, Piauí e Paraná (Nosso Jornal, Curitiba, Ano II, no 75, março, 1948). Mesmo na Bahia-que segundo Thales de Azevedo (1975), havia uma grande desconfiança, já que não havendo racismo, não haveria necessidade de um "movimento isolacionista" - foi estabelecida uma sucursal do grupo, sob a direção de Petronildo Mattos. Em São Paulo, os conselheiros eram Raul Joviano do Amaral, antigo membro da Frente Negra, e Luiz Lobato, comunista de velha cepa. À medida que ia se expandindo, a UHC constituía novas sucursais pelo país. A UHC do Distrito Federal, por exemplo, coordenada por José Bernardo da Silva e Jovino Severino de Mello, foi fundada em 1949.

A União dos Homens de Cor dos Estados Unidos do Brasil ou UAGACÊ, como costumava ser chamada - tinha como um dos seus objetivos, expressos no artigo $1^{\circ}$ do estatuto, no capítulo das finalidades: "elevar o nível econômico, e intelectual das pessoas de côr em todo o território nacional, para torná-las aptas a ingressarem na vida social e administrativa do país, em todos os setores de suas atividades". A rede constituía-se de uma complexa e sofisticada estrutura organizativa, já preconizada desde os seus primórdios. As diretorias estaduais e municipais dividiam-se nos cargos de presidente (no município, denominava-se presidente ou chefe municipal), secretário geral (no município eram primeiro e segundo secretários), tesoureiro, inspetor-geral, chefe do departamento de saúde e conselheiros/diretores. Os departamentos de saúde e de educação, em alguns estados, estavam sob a coordenação da mesma pessoa. A diretoria nacional, composta pelos fundadores, possuía a mesma formação que as estaduais, diferenciando-se apenas pela existência de um consultor jurídico. $\mathrm{O}$ grupo se sustentava nacionalmente numa rede articulada por chefes municipais da capital. $^{8}$

Em 1948, a UHC do Paraná registrava 26 zonas municipais da capital. Já no interior do estado, a rede mantinha-se a partir de inspetorias regionais que concentravam chefias municipais da mesma região, num total de 23 cidades. ${ }^{9}$ No caso das diretorias municipais, havia uma recomendação para que os diretores procurassem "incluir senhoras e senhoritas nas diretorias em cargos de responsabilidade". ${ }^{10}$ É interessante notar que a UHC pretendia uma abrangência nacional, estabelecendo-se em todos os estados. Assim, um de seus periódicos traz uma recomendação, encaminhada a todos os tesoureiros, de que estaria vetada a cobrança das mensalidades aos associados ( 1 cruzeiro), até que uma ordem dire- 
ta da diretoria geral outorgasse tal recebimento. A nota prossegue informando que só quando a "UHC estiver organizada em todo o país, poderá ser feita a cobrança”. A convenção anual era realizada a cada 13 de maio na sede nacional em Porto Alegre, com a presença de representantes estaduais eleitos pelos chefes municipais, cuja relação de nomes deveria ser publicada com a devida antecedência.

A UHC valia-se da estrutura política já estabelecida nos locais em que estivesse presente. Assim, deputados, médicos, advogados, jornalistas e homens negros com visibilidade social e política eram convidados a integrar a organização e tinham na rede um sustentáculo. Vários são os exemplos que poderiam ser dados para registrar este fato de que homens negros socialmente destacados são incluídos na rede. Um deles, o Presidente da UHC do Paraná em 1948, Nilton Oliveira Condessa, era advogado, jornalista e professor da Faculdade de Ciências Econômicas do Estado. O médico baiano, radicado em Londrina e deputado estadual, Justiniano Climático da Silva, também era membro da organização. ${ }^{11} \mathrm{O}$ outro exemplo é o de Antenor Pantilo dos Santos, vereador em $\mathrm{Cu}$ ritiba, em 1948, pelo PSD. Ou seja, estas lideranças fortaleciam-se politicamente, em nível local, por estarem ligadas a uma conexão nacional de homens negros com destacada atuação social e política nas suas regiōes. Ao mesmo tempo, auxiliavam a UAGACÊ na expansão dos seus tentáculos que se espraiavam nas capitais, sobretudo nos municípios de cada estado, sob a orientação de uma direção estadual.

Esteve entre nós o nosso consórcio Dr. Fernando Lopes de Oliveira, do Distrito Regional de Arapongas e diretor do Distrito do Jornal Arapongas. Prestando esclarecimentos sobre o andamento de nosso trabalhos na região sob sua jurisdição, disse-nos S.S. da simpatia com que o povo tem acolhido a nossa sociedade [...]. Esperando-se que atinja em breve a apreciável cifra de dez mil membros [...]. A Inspetoria Regional de Arapongas compreende os municípios de Arapongas, Londrina, Assaí, Cornélio Procópio, Apucarana e Uraí. (Fernando Lopes de Oliveira, Nosso Jornal, Ano II, no 75, p. 2, 27.3.1948, Curitiba).

O Nosso Jornal, seu informativo e órgão de difusão, podia ser impresso e reproduzido em cada município, desde que se articulasse com a coordenação geral do seu estado. Como resultado, a rede, que era estruturada a partir de um presidência central, tornava-se autônoma e mais ágil no alcance de seus objetivos. Dentre as atividades desenvolvidas estavam as campanhas educacionais, cuja meta principal era a integração do negro na sociedade através da ascensão social e intelectual, a fim de permitir sua inclusão. A ideo- 
logia liberal de mobilidade, ascensão e inclusão social através dos bancos escolares era perseguida por aquele grupo de emergentes.

A UHC tem por finalidades manter moços e moças em cursos superiores, concedendo-lhes roupa, alimentação, etc. para que possam concluir os estudos [...]. E ampla campanha de alfabetização, de forma que, dentro de 10 anos não exista um único homem de côr que não saiba ler. ${ }^{12}$

Note-se que a educação formal e a preparação profissional foram sempre perseguidos pelos negros organizados, em diferentes épocas. A Frente Negra Brasileira em São Paulo, nos anos 1930, constituiu extensas turmas de alfabetização. Os diretores fundadores do Renascença Clube do Rio de Janeiro (nos anos 1950) chegavam mesmo a comprar livros para os alunos em dificuldades. $\mathrm{O}$ TEN criou escolas de atores e aulas de alfabetização. A União Cultural dos Homens de Côr do DF constituiu diversos cursos de corte e costura para empregadas domésticas. Outro ponto do seu estatuto determinava que todos os seus membros alfabetizados deveriam tomar para si a responsabilidade de alfabetizar pelo menos uma pessoa ligada aos seus quadros, garantindo, desta forma, que no fufuto todos os que a ela fossem filiados, deixassem de ser analfabetos.

Além da educação, a UHC dedicou-se a atender os problemas mais imediatos e visíveis ligados às mudanças sociais e educacionais para os negros no geral e para aqueles associados a ela.

Daí depreende-se que a UAGACÊ não pretende estimular o preconceito de cor. Inversamente, até quer diluí-lo de todo, combatendo-o da melhor maneira possível, no entender de seus dirigentes: educando e instruindo o negro para que ele, uma vez capacitado a desempenhar melhores encargos, possa fazer vida social em comum com os brancos. ${ }^{13}$

Desta forma, o direito à moradia, também como estratégia de inclusão e ascensão social, era parte dos objetivos da entidade:

A UHC (com Deus pela Pátria e a família) tem finalidades assistenciais: construir casas próprias para famílias e residências coletivas para homens e mulheres. ${ }^{14}$

Fundada em Teresópolis, região serrana do Estado do Rio de Janeiro, a UHC daquela cidade tinha como uma de suas principais metas adquirir terrenos para a construção de "casas de tijolos e telhas higiênicas, assoalhadas em condiçōes de serem habitadas".

A saúde era outra de suas metas. Desenhava-se um modelo de previdência privada através da "Assistência médica a todos os 
membros da União" ${ }^{16}$ a serem atendidos por profissionais especializados pertencentes à UHC, no qual em cada município deveria haver um médico ou cirurgião-dentista voltados aos membros da entidade. O estatuto, no entanto, deixa claro que estes voluntários deveriam "perceber honorários correspondentes aos serviços prestados". Afastava-se assim a visão de voluntariado ou assistencialismo. Era, isto sim, um sistema de previdência social a ser estabelecido como forma de suprir a ausência do estado.

O capítulo do estatuto geral - que deveria ser aplicado por todos os ligados à UAGACÊ, em âmbito nacional - refere-se a "um programa pré-eleitoral de partido político", que foi desenvolvido em muitas localidades. Seu fim era procurar eleger lideranças da rede UHC nas eleiçôes municipais e estaduais. O presidente da UHC do Distrito Federal, por exemplo, foi eleito deputado estadual em 1950.

Assim, presentes na educação, na saúde e na política institucionalizada, acreditavam os da UHC que estariam abrindo caminho para o "alevantamento moral das pessoas de côr". A assistência social era, então, o caminho mais imediato para se conseguir este objetivo. Em muitos eventos, a UHC aproximava-se do perfil das antigas irmandades religiosas ao organizar caravanas de doação de roupas, alimentos e medicamentos aos pobres.

\section{Ultrapassando as caravanas assistenciais: estratégias políticas}

Um dos poucos estudos já realizados sobre a UHC foi feito por Costa Pinto a respeito de sua sucursal do Rio de Janeiro. A comparação direta com o TEN leva o autor a interpretá-la muito mais como uma das associações intermediárias do que aquelas que propõem uma mudança de parâmetros na sociedade brasileira. À primeira leitura do estatuto da UHC, pode-se pensar que sua tarefa fosse apenas de assistência social ou de simples iniciativas de "estratégias integracionistas e assimilacionistas” (Santos, 1986: 289). No entanto, uma observação mais atenta sobre suas iniciativas, deixa transparecer uma maior abrangência de ações, como veremos posteriormente e como se pode observar numa entrevista dada a um dos periódicos da imprensa negra do Rio de Janeiro, pelo seu presidente estadual:

A UHC, por intermédio do seu presidente, faz apêlo para que seja abandonada a idéia geral que é a falta de cultura que caracteriza o desajustamento do negro na sociedade brasileira. Nós temos negros de valor [...] 
Isto demonstra ao mundo que não há raça superior em face das raças judaicas e negras, as mais perseguidas no mundo.

Seus líderes chegavam, algumas vezes, a sugerir uma possível crítica ao sistema, sem, contudo, reivindicar uma postura de confronto com o Estado ou seus representantes. "Os administradores, em 63 anos de abolição, não fizeram jus, de um certo modo, às reivindicações da causa abolicionista. Porque nós vivemos geralmente afastados dos altos cargos da administração pública”.

Uma das estratégias adotadas era organizar-se a partir do estabelecimento de parcerias e alianças com personalidades e autoridades locais, não negras, que se mostravam sensíveis a uma cruzada anti-racista no país. A UHC do Distrito Federal realizou uma homenagem por ocasião do centenário de José do Patrocínio, para a qual afluíram importantes lideranças da cidade de Campos (RJ), em 1949. A atividade foi possível devido ao concurso de um deputado estadual, cujo projeto teria permitido a realização da homenagem. Nesta tática de arrebanhar presentes e futuros aliados, as palavras finais do conferencista nos permitem vislumbrar esta metodologia.

Quero pedir ao deputado Celso Peçanha, autor principal do projeto que tanto serviu para dar a esse preito de veneração um cunho menos regional, que não se esqueça de que é campista e carrega a responsabilidade do sobrenome daquele que serviu de amparo ao sonho do homenageado. Os homens vigilantes sois vós campistas, que certamente providenciareis para que o grupo étnico que vos deu um Patrocínio dê centenas de outros Patrocínios a fim de que se projetem todos eles pelo Brasil inteiro e lutem pela culturação e educação de seus irmãos de côr. ( José Bernardo da Silva, Nosso Jornal, outubro de 1950, p. 4)

Lembremos que José do Patrocínio esteve prestes a criar um dirigível e foi por isto duramente combatido pelos políticos e autoridades da época. Dentro do pequeno grupo de defensores estava Nilo Peçanha, de quem o aludido deputado era herdeiro. Assim, ao evocar este fato histórico, cem anos depois, usando o sobrenome do deputado presente (Peçanha), o orador procurava comprometê-lo numa causa mais ampla, que ultrapassasse o momento da homenagem a uma liderança histórica. ${ }^{17}$ Tornava-o partícipe e suposto seguidor de uma tradição, iniciada por um de seus ancestrais, de vir a público aliar-se aos negros de forma a coibir injustiças e discriminações. Dito de outra forma, o representante da UHC procurava restabelecer uma aliança iniciada um século antes e assim elaborar uma parceria possível. 
Os líderes da UHC demonstravam estar atualizados com o fluxo de discussões acadêmicas e científicas da época, através das reflexôes pioneiras que provocavam. Um de seus jornais, publicado em Santa Catarina em 1950, estampa uma frase da autoria de Donald Pierson.

Outro exemplo neste sentido é um trecho do discurso pronunciado durante as festividades do centenário de José do Patrocínio (1949), pelo segundo homem na hierarquia da entidade no Distrito Federal:

Nós, da União dos Homens de Cor, temos sido combatidos no nosso sonho humanístico de vermos os pretos e pardos do Brasil dignificados pela cultura, educação e moral [...] Uns nos combatem por não saberem dos nossos reais intuitos, outros fazem isto por adotarem as idéias de Gobineau, um dos pais do racismo.

O tom quase intimista com que Gobineau é citado nos permite observar que as teses científicas transpunham-se dos compêndios acadêmicos e eram lidas pelas lideranças negras da época. Assim, um dos artigos refere-se à "lastimável incúria em que estiveram os estudos sobre o negro no Brasil” e segue numa crítica ácida em relação aos trabalhos de Spix e Martius e de como "a autoridade de ambos" teria levado a conclusões equivocadas a respeito das populações africanas chegadas ao Brasil. Reiterando a tese da destruição dos documentos, que poderia atestar os números e a origem real dos africanos trazidos ao Brasil, o jornal passa por Silvio Romero, critica negativamente o seu trabalho e conclui fazendo uma longa enumeração dos vários povos africanos que aqui vieram e para quais estados ou regiōes foram transportados. ${ }^{18}$ Esta atualidade sobre as idéias consentâneas do mundo e na ausência de maiores instrumentos legais aos quais se referir - a Lei Afonso Arinos ainda não havia sido sancionada - a Declaração Universal do Direitos Humanos, recém-publicada pela ONU, passou a servir de parâmetro a subsidiar aquela rede.

Ações de governo que pudessem reverter, direta ou indiretamente, benefícios à população negra eram focalizados e relatados no seu periódico. Em outras palavras, as políticas que tivessem como alvo o benefício da população pobre eram repercutidas no jornal. Outra estratégia adotada era - tendo como um de seus objetivos o "combate a todo tipo de descriminação racial" [extrato do estatuto] - promover movimentos de pressão que davam visibilidade e serviam como denúncia pública de situações de racismo e 
discriminação racial, como informava José Bernardo da Silva, presidente da UHC do Distrito Federal, nos anos 60.

Assim que Getulio Vargas fora eleito Presidente da República, estivemos com Sua Excelência expondo-lhe as aspirações da UHC e pedindo o seu apoio. Queríamos que Vargas nos facilitasse os meios necessários para fundarmos escolas até mesmo profissionais e órgãos assistenciais em benefício dos pretos e pardos atirados à margem da sociedade e sofrendo mais que os brancos [...]. Nada de positivo resultou dessa entrevista. A documentação que entregamos ao então presidente da República não sabemos que destino tomou.

Costa Pinto refere-se à visita feita por um de seus diretores à uma firma norte-americana em companhia da imprensa. O objetivo era exigir um ato de desagravo por parte do gerente que negara emprego a uma mulher negra (Pinto, 1952). Outra ação de pressão foi a campanha de inclusão de negros nas propagandas oficiais. $\mathrm{O}$ racismo brasileiro acabava sendo visibilisado internacionalmente, a partir da participação da UHC no Conselho das Organizações não Governamentais pertencente ao escritório da UNESCO no Rio de Janeiro.

Percebemos, então, que embora a visibilidade da organização se desse através das caravanas de doações de roupas, alimentos e remédios, estas funcionavam apenas como um grande outdoor, diante do qual desfilavam açôes mais contundentes dos diversos grupos da rede, espraiados pelo país. Assim sendo, as parcerias políticas, as pressóes contra as autoridades constituídas e as críticas em relação às teorias raciais que atribuíam ao negro as marcas de inferioridade eram estratégias que demarcavam as verdadeiros objetos UHC. Ainda nesta linha estratégica de defesa de direitos civis, o emprego da Declaração Universal dos Direitos Humanos, recém-elaborada pela ONU, os colocava em diálogo direto com as reivindicações por cidadania correntes para além das fronteiras do estado brasileiro.

\section{Conclusão}

O novo momento político e econômico da redemocratização após a ditadura Vargas estimulou o aparecimento de manifestaçôes negras de diversas naturezas. O movimento social dos negros estava, então, em constante interlocução com os mecanismos estabelecidos pela sociedade buscando influenciá-la e sendo por ela influenciado. A criação e a expansão da UHC foi precipitada 
por três fatores principais: em primeiro lugar, havia a discrepância entre a identidade de racialmente inferiores, atribuída aos negros, e sua crescente ascensão social e cultural, que acabava por criar barreiras socioestruturais para a sua inclusão político-social. Em segundo lugar, estava o surgimento de diversas formas organizativas que permitiam aos negros aglutinarem-se em torno de questóes com as quais se identificavam. Ou seja, havia uma atmosfera que estimulava a criação de novas entidades e aquecia os debates em torno dos direitos a serem conquistados. $\mathrm{O}$ terceiro fator repousa na influência da circulação de idéias no mundo, onde o retorno da racialização preocupava a todos. Era a luta contra o racismo empreendida em âmbito mundial dentro do espírito político e ideológico do pós-guerra, quando os documentos da ONU, criados para este fim, ajudavam a estabelecer bases e critérios para uma cruzada anti-racista.

Ao longo de sua trajetória, que se iniciou no pós-guerra, estabeleceu-se nos anos 50 e expandiu-se pelos 60, a UHC buscava reconhecimento para os negros no âmbito do Estado-nação brasileiro. Se considerarmos que, pautado no discurso liberal e universalista, o nacionalismo tende a estimular a negação das diferenças (Anderson, 1994/ Mauss, 1969), o Estado brasileiro era em sua formação excludente e discriminador. Então, a UHC e muitos dos grupos seus contemporâneos, mais do que tratar de inclusão e ascensão social, buscavam a participação dos negros no projeto nação brasileiro. A luta era, então, contra o Estado, na sua forma racializada. Em última análise, suas ações buscavam inseri-los no Estado-nação, a partir da participação igualitária nas instâncias de poder nacionais. Um exemplo que poderíamos citar seria a preocupação constante - demonstrada em suas publicaçõos - em inserir seus representantes em cargos eletivos e a atração de negros parlamentares (estaduais ou municipais) para aliarem-se aos quadros da organização.

Desta forma, o estudo da trajetória da UHC pode nos auxiliar a perceber a construção de identidades que embora tenham a etnicidade como base de construção, apresentam-se, ao mesmo tempo, diversas e heterogêneas em suas formas de expressão. Estudar o passado pode nos ajudar a observar o quanto diferentes práticas e manifestações culturais e políticas contribuíram para a organização dos negros no presente. 


\section{Notas}

1. A esse respeito nos fala Santos: "O espetáculo era insólito: viam-se negros operários (e sobretudo após o estancamento da imigração); negros biscateiros; negros pequenos empresários (quase sempre comerciários públicos (militares, sobretudo, mas também administrativos); negros radialistas, jogadores de futebol, cabos eleitorais as profissões que a Revolução inventou; e assim por diante" (Santos, 1985:288).

2. "O próprio Geraldo dirigiu o Teatro e com a renúncia de Jânio, aquela confusão, o Geraldo foi para o Rio de Janeiro com um cargo no Ministério do Trabalho e deixou o teatro na mão do de um jovem chamado Dalmo Ferreira. O Dalmo pegou todo o teatro e fez uma reviravolta, porque em vez do teatro ser um grupo que ia levar peças tradicionais, o Dalmo fez um tipo de teatro popular, intercalando de músicas, pegando as nossas coisas, aí começou esse tipo de teatro”. (Aristides Barbosa apud Márcio Barbosa, (1998:32).

3. Jornal Quilombo, Ano I, no 4, p. 9, julho de 1949.

4. Fundado por Solano e Margarida Trindade e Edson Carneiro em 1950.

5. Pela extensão e alcance de sua atuação, o TEN mereceria um capítulo específico neste trabalho. Evitamos fazê-lo num esforço de não desviar de nosso foco principal, que é atuação da UHC. A esse respeito, sugerimos a leitura de Nascimento (1999), revista Thoth (no 1, 1997), Hanchard (1998), Mendes (1993), Andrews (1991).

6. Entrevista dada à autora por Efigênia Carlos Pimenta, filha do fundador e atual militante do movimento negro de Belo Horizonte ( junho, 2003) .

7. Embora fundada em 3 de janeiro de 1943 , o registro de seu estatuto ocorre em janeiro de 1946. Acreditamos que esta defasagem se deva ao fato de que a diretoria tenha achado por bem aguardar o período da ditadura varguista, para só então oficializar a organização.

8. "Os chefes municipais nomearão um distrital para cada distrito de seus municípios, os quais organizarão as respectivas diretorias, compostas de tantos membros quantos se façam necessários, observando sempre a organização das diretorias dos municípios" (Nosso Jornal, 27.3.1948, Ano II, no 75, p. 4, Curitiba).

9. "É uma sociedade legalmente registrada para todo o país, existindo uma diretoria para toda a nação, uma diretoria em cada município com um único estatuto" (extrato do estatuto)

10. Nosso Jornal, Ano II, no 75, p. 4, 27.3.1948, Curitiba.

11. Cf. Nosso Jornal, janeiro de 1948, Curitiba.

12. João C. Alves, jornal Quilombo, Ano I, no 1, p. 3, dezembro de 1948.

13. Jornal Quilombo, Ano I, no 1, 9.12. 1949, p. 3.

14. Depoimento de João C. Alves, jornal Quilombo, Ano I, no 1, p. 3, dezembro de 1948.

15. Jornal Redenção, 30.12.1950, p. 3.

16. Cf. jornal Quilombo, Ano I, no 1, p. 3, dezembro de 1948.

17. José do Patrocínio, Cruz e Souza, Luiz Gama e Henrique Dias eram os grandes heróis negros homenageados por diversos grupos em âmbito nacional.

18. Nosso Jornal, outubro de 1950, Curitiba. 


\section{Referências bibliográficas:}

ANDERSON, Benedict (1994). Imagined Communities. Lundu, Verso.

ANDREWS, George Reid (1991). Blacks and whites in São Paulo, Brasil. 1888-1988. The University of Wisconsin Press.

BARBOSA, Márcio (org.) (1998). “Frente Negra Brasileira: Depoimentos/entrevistas e textos". Quilomboje, São Paulo.

BASTIDE , R. \& FERNANDES F. (1971). Brancos e negros em São Paulo. (3a ed.). São Paulo, Cia. Editora Nacional.

GUIMARÃES, Antonio Sérgio Alfredo e Hunley, Lynn (org.) (2000). Tirando a máscara: ensaios sobre o racismo no Brasil. São Paulo, Paz e Terra.

(1999). Racismo e anti-racismo no Brasil. São Paulo, Ed. 34.

HALL, Stuart (1999). A identidade cultural na pós-modernidade. Rio de Janeiro, DP\&A.

HANCHARD, Michael George (1998). Orpheus and Power. The Movimento Negro of Rio de Janeiro and São Paulo, Brasil 1945-1988. Princeton, NJ, Princeton University Press.

MENDES, Miriam Garcia (1993). O negro e o teatro brasileiro. São Paulo, Hucitec.

MOURA, Clóvis (1988). História do negro brasileiro. São Paulo, Editora Ática.

_ (1988). Sociologia do negro brasileiro. São Paulo, Editora Ática.

NASCIMENTO, Abdias (1968). "Teatro negro no Brasil, uma experiência sócioracial”. Revista Civilização Brasileira, $\mathrm{n}^{\circ}$ 2, caderno especial.

_ (1982). O negro revoltado (2a ed.). Rio de Janeiro, Editora Nova Fronteira.

NASCIMENTO, E. L. (1999). Sortilégio da cor: identidade afro-descendente no Brasil. Tese de doutorado em Psicologia, Instituto de Psicologia da Universidade de São Paulo, Departamento de Psicologia da Aprendizagem, do Desenvolvimento e da Personalidade.

PEREIRA, Amaury Mendes (1988). Emergência e ruptura. Uma abordagem do movimento negro na sociedade brasileira. Tese submetida ao corpo docente do curso de Pós-Graduação em História da África, Centro de Estudos Afro-Asiáticos, UCAM, mimeo.

SILVA, Joselina da (2000). Renascença, lugar de negros no plural. Construções identitárias em um clube social de negros no Rio de Janeiro. Dissertação de Mestrado em Ciências Sociais apresentada à Universidade do Estado do Rio de Janeiro - UERJ.

SILVA, Maria Auxiliadora Gonçalves da (1994). Encontros e desencontros de um Movimento Negro. Brasília, Fundação Cultural Palmares.

SOUZA, Marilúcia dos Santos. "O debate étnico e a União dos Homens de Cor de D. de Caxias”. Pilares da História, órgão de divulgação do Instituto Histórico Vereador Thomé Siqueira Barreto, Duque de Caxias, Rio de Janeiro.

SODRÉ, Muniz (1999). Claros e escuros: identidade, povo e mídia no Brasil. Petrópolis, Vozes.

SANTOS, Joel Rufino dos (1985). "O movimento negro e a crise brasileira". Revista de Política e Administração, vol. 2, no 2, jul./set., pp. 287-307.

WINANT, Howard (1994). Racial conditions: politic, theory, comparisons. University of Minesotta Press. 
A União dos Homens de Cor: aspectos do movimento negro...

\section{Jornais:}

Alvorada, São Paulo, maio de 1945, setembro de 1946 e janeiro de 1948.

Novo Horizonte, São Paulo, Ano VIII, no 65, outubro de 1954

Nosso Jornal, Curitiba, dezembro de 1950.

Quilombo, Rio de Janeiro, Ano I, no 1, dezembro 1948 e Ano I, no 4, julho de 1949.

\section{Revistas:}

Senzala: Revista mensal para o negro, Ano I, no 1, janeiro de 1946, São Paulo. Thoth, no 1, 1997. Brasília, Gabinete do Senador Abdias do Nascimento. 